\title{
Pengembangan Prototipe Smart Blade pada Turbin Angin berbasis Servo Pneumatik
}

\author{
1Nuryanti*), ${ }^{1}$ Ridwan, ${ }^{1}$ Muhammad Ramadhan \\ Teknik Otomasi Manufaktur dan Mekatronika Politeknik Manufaktur Bandung \\ nuryanti@polman-bandung.ac.id ${ }^{*}$ \\ ridwan@polman-bandung.ac.id*)
}

\begin{abstract}
Abstrak
Sistem otomasi pada smart blade sebagai kontrol kecepatan angin jika mencapai maksimal. Karena Daya angin sebanding dengan pangkat tiga kecepatan maka kecepatan angin yang melebihi kecepatan maksimal dapat melonjakkan daya sehingga generator mengalami kelebihan kapasitas selain itu getaran turbin yang terlampau kencang dapat menyebabkan kerusakan pada konstruksi penopang turbin. Oleh karena itu kontrol pitch menjadi salah satu metode untuk membatasi kecepatan angin di atas kecepatan Cut Out. Kontrol pitch atau kontrol sudut baling-baling mengubah sudut serang angin sehingga penangkapan angin berkurang dan pergerakan turbin tidak melampaui batas maksimal. Pembuatan prototype kontrol pitch telah dilakukan baik pada aspek mekanik yaitu pembuatan aktuator berbasis pneumatik yang dapat menggerakkan pitch dan sistem sensor dengan pemrograman pada mikrokontroler. Untuk metode kontrol menggunakan metode cascade dimana komponen-komponen yang digunakan meliputi encoder incremental, silinder pneumatik, mikrokontroler, potensiometer geser, dan katup pneumatik 5/3. Berdasarkan hasil pengujian yang telah dilakukan, hasil pengukuran kecepatan putar turbin angin tanpa pitching mencapai $80 \mathrm{rpm}$ dan kecepatan saat pitching mencapai $0 \mathrm{rpm}$. Namun pada kontrol cut out kecepatan turbin angin dalam melakukan pitching ditetapkan pada nilai $40 \mathrm{rpm}$. Pergerakan silinder penumatik dengan pembebanan (plant) dapat bergerak sebesar $8 \mathrm{~mm}$. Sedangkan pergerakan tanpa pembebanan dapat mencapai error maksimum sebesar 22,4 \% dengan rata-rata error $7,13 \%$. Dengan diterapkannya metode pitching pada prototipe turbin angin, kecepatan turbin angin dapat dibatasi.
\end{abstract}

Kata Kunci: turbin angin, kontrol pitch, servo pneumatik

\section{Pendahuluan}

Dalam pengembangan Pembangkit Listrik Tenaga Bayu (PLTB) di Indonesia salah satu kendala nya adalah fluktuasi kecepatan angin. Fluktuasi di sini adalah berubahrubahnya kecepatan angin dari kecil ke besar atau sebaliknya dalam waktu singkat. Atau adakalanya angin tidak berhembus samasekali. Oleh karena itu pada sistem smart blade atau smart rotor yang didefinisikan sebagai suatu unit sistem yang dapat merasakan gangguan kemudian mengkomputasikan reaksi secara aktif untuk mengendalikan beban aerodinamik sebagai respon terhadap gangguan tersebut [1]. Salah satu smart blade adalah blade yang dilengkapi sistem kontrol pada Pitch atau pada yaw. Pada pitch yaitu pada pangkal blade/bilah, sedangkan yaw adalah pada leher rotor. Pada kontrol pitch dimana blade dapat bereaksi terhadap gangguan berupa kecepatan angina yang terlalu tinggi atau di atas kecepatan angina Cut Out kemudian dengan mikrokontroler dapat mengkomputasikan gangguan tersebut dengan memberikan reaksi berupa pergeseran sudut pitch melalui servo pneumatik. Pada sistem kontrol Pitch dilakukan untuk mencegah terjadinya daya dan getaran berlebih jika terdapat angin dengan kecepatan di atas kecepatan Cut Outnya dengan asumsi angin bergerak sejajar dengan arah normal rotor. Karena daya sebanding dengan pangkat tiga kecepatan angin sehingga angin kencang akan menghasilkan lonjakan daya yang diluar kapasitas generator, selain itu dengan getaran yang berlebih dapat membuat aus sistem atau berpotensi mematahkan bilah.

Sejauh ini penelitian pada pitch kontrol dimana pergerakan blade atau bilah yang dapat merespon beban aerodinamik akibat angin kencang masih banyak yang baru pada tahap konsep simulasi modelling. Seperti yang dikembangkan oleh Bossanyi et al [2] dengan melakukan kontrol per-bilah sehingga dapat menanggung beban asimetris. Metode pengontrolannya dengan mengembangkan algoritma Linier-Quadratic-Gaussian Control (LQG) yang dapat mengatasi masalah dengan multivariable. Begitupula yang telah dilakukan oleh Andersen [3] yang menemukan perancangan bilah inovatif dimana terdapat bagian yang membuka dan menutup untuk mengurangi beban aerodinamik (sistem Deformable Trailing Edge Geometri, DTEG) dan menggunakan 
kontrol LQG dan PID. Keduanya melakukan simulasi dengan menggunakan software untuk menganalisa sejauh mana sistem kontrol tersebut dapat mengatasi permasalahan. Meski secara simulasi menunjukkan hasil yang baik namun Bossanyi masih menyarankan untuk melakukan modifikasi jika akan diaplikasikan karena model turbin nyata mungkin berbeda dengan model yang dibuat. Untuk penelitian yang dikembangkan yaitu penelitian pada bagian kontrol pitch sudah dilakukan baik dengan merancang sistem mekanik, sistem elektropneumatik, maupun sistem kontrol dengan menggunakan mikrokontroler. Prototipe yang dibangun yaitu blade yang dilengkapi bagian mekanik untuk melakukan perubahan sudut bilah sehingga bilah akan berhenti jika dikenai kecepatan di atas kecepatan Cut Out. Bagian servo pneumatik yang terdiri atas potensiometer geser, katup silinder 5/3 dan silinder double acting. Metode kontrol dengan menggunakan pneumatik didasari atas beberapa pertimbangan antara lain aplikasi untuk pembangkit listrik skala kecil (kurang dari $100 \mathrm{KW}$ ). Sedangkan jika aplikasi skala Megawatt menggunakan hidrolik sebagai sistem aktuasi kontrolnya.

Proses penangkapan energy angin dipengaruhi oleh factor luas permukaan penampang rotor yang dipengaruhi oleh diameter bilah dan juga factor lainnya yaitu sudut serang rotor terhadap angin. Sudut serang yang paling optimal menurut AR.Jha adalah 0.1 radian atau 5.73 derajat [4]. Sudut serang yang dimaksud adalah sudut antara angin yang datang terhadap garis normal rotor. Sehingga secara umum rotor selalu berhadapan dengan datangnya angin. Sudut serang yang semakin besar akan menurunkan daya tangkap angin. Adapun daya angin (Pdelivered) dirumuskan sebagai [5]:

$P_{\text {delivered }}=C_{p} \cdot \frac{1}{2} \rho A v^{3}$

Dengan $C_{p}$ adalah koefisien daya, $\rho$ adalah masa jenis udara, A adalah luas penampang yang disapu oleh turbin, dan $v$ adalah kecepatan angin. Di sini dapat kita lihat bahwa daya angin sebanding dengan pangkat 3 dari kecepatan angin. Koefisien daya menunjukkan efisiensi aerodinamik turbin dan sebagai fungsi dari tip speed ratio, $\lambda$. Dimana $\lambda$ didefinisikan sebagai :

$$
\begin{aligned}
& \lambda=\frac{V_{\text {blade }}}{V_{\text {angin }}} \\
& \lambda=\frac{\omega R}{v}
\end{aligned}
$$

Dengan $\omega$ adalah kecepatan putar bilah, $\mathrm{R}$ adalah panjang bilah (jari-hari turbin). Atau tip speed ratio adalah perbandingan antara kecepatan bilah atau turbin dengan kecepatan angin.

\section{Perancangan Sistem}

\subsection{Gambaran Umum Sistem}

Untuk mengendalikan bilah agar tidak bergerak saat angin di atas Cut out, maka sudut pitch diubah sehingga bilah tidak menangkap angin secara maksimum dan rotor tidak lagi berputar. Seperti terlihat pada Gambar 1 dimana dari encoder diketahui kecepatan angin yang sebanding dengan putaran turbin yang pergerakannya melalui gearbox. Jika kita masukkan set point yaitu nilai kecepatan angin tertentu (disesuaikan dengan kapasitas turbin), maka Jika kecepatan terukur $\left(\mathrm{V}_{\text {measured }}\right)$ lebih besar dari kecepatan setpoint ( $\mathrm{V}_{\text {set }}$ point $)$ maka Pitch controller akan bekerja mendorong pitch actuator untuk mengubah sudut pitch, sehingga rotor akan berhenti.

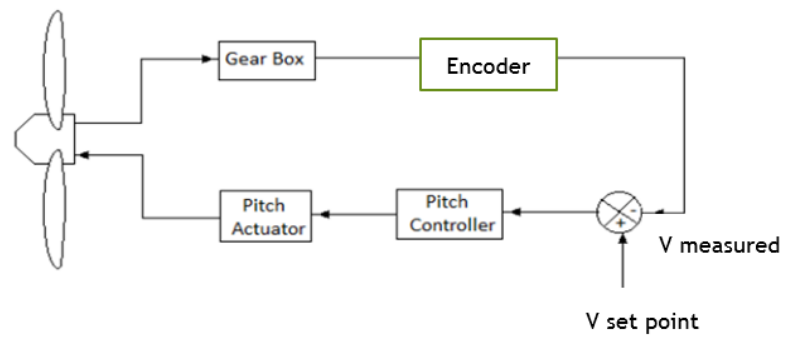

Gambar 1 Gambaran umum sistem

Dapat dilihat pada Gambar 2 rancangan mekanik smart blade dimana terdapat bagian batang bilah (1), bagian yang mentransfer pergerakan linier silinder menjadi pergerakan sudut bilah (2) dan actuator berupa silinder pneumatik (3) 


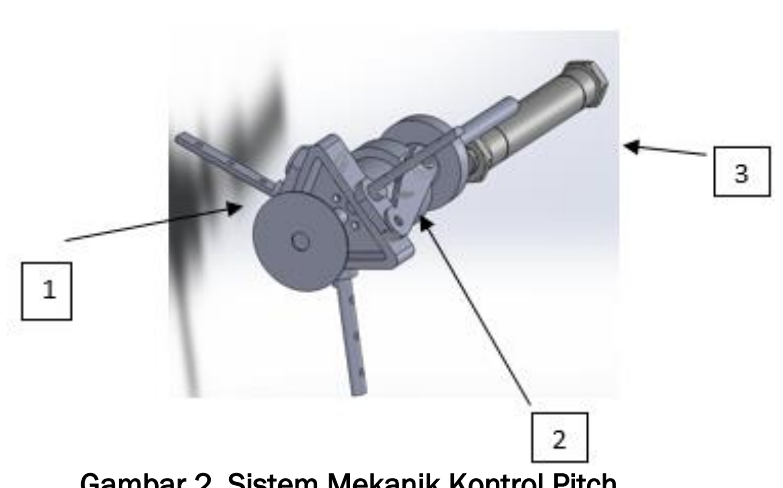

Gambar 2. Sistem Mekanik Kontrol Pitch

\subsection{Konsep Sistem Kontrol Pitch dengan Servo \\ Pneumatik}

Pengendalian sistem dilakukan oleh sebuah mikrokontroler Arduino Mega baik dalam pembacaan sensor ataupun memberi perintah pada aktuator. Arduino Mega menerima data pembacaan kecepatan putar turbin dari sensor encoder incremental dan menerima pembacaan sudut baling-baling dari sensor potensiometer geser. Pengolahan data yang didapat dari sensor dilakukan oleh Arduino Mega untuk menghitung error antara kecepatan putar motor dari encoder (berupa kecepatan linier dalam satuan meter/detik) dengan posisi baling-baling dari linier potensiometer. Jika terjadi error/kecepatan motor berkurang, maka mikrokontroler akan memberi sinyal pada aktuator berupa katup pneumatik untuk menjalankan silinder agar sudut balingbaling dapat berubah untuk menyesuaikan kecepatan putar turbin.

Sudut baling-baling dapat berubah secara variatif karena digerakkan oleh engkol yang berfungsi seperti siku dimana ujung engkolnya digerakkan oleh aktuator pneumatik. Aktuator yang digunakan dalam tugas akhir ini merupakan silinder pneumatik SKC MAL 20-50 yang dikendalikan oleh sebuah katup. Katup yang dipakai adalah katup SMC 5/3 closed center dengan pemilihan ruang tengah yang tertutup (closed center). Pemilihan katup closed center dimaksudkan agar silinder pneumatik dapat beroperasi lebih dari dua posisi yang umum (awal - akhir) sehingga memungkinkan untuk berhenti di tengah, agak menengah, agak akhir. Hal ini sangat diperlukan untuk pengendalian balingbaling sehingga dapat berputar dalam sudut yang bervariasi. Sensor umpan balik yang digunakan untuk silinder pneumatik adalah potensiometer geser yang dihubungkan pada mikrokontroler. Data dari potensiometer dan encoder akan ditampilkan pada LabVlew visa. Konsep sistem dapat dilihat pada gambar 3 .

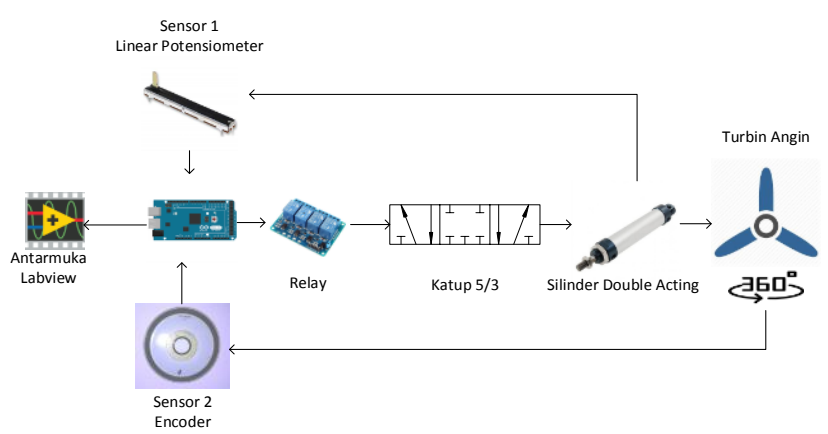

Gambar 3. Konsep sistem kontrol pitch dengan servopneumatik

Servopneumatik memungkinkan pergerakan yang disesuaikan dengan posisi. Adapun bagian servopneumatik terdiri dari :

a. Silinder double acting sebagai aktuator

b. Katup 5/3 sebagai komponen proses yang memungkinkan silinder berhenti di antara posisi maksimum dan minimumnya

c. Relay sebagai elemen proses yang memungkinkan sinyal input elektrik dari mikrokontroler yang dapat menyalakan solenoid pada silinder

d. Sensor Linier Potensiometer sebagai sensor posisi dari beban dan silinder

\subsection{Diagram Alir Sistem}

Diagram alir sistem menjelaskan tentang logika kerja sistem pada penelitian ini. Diagram terdiri dari satu diagram umum kontrol. Diagram kontrol secara umum dapat dilihat pada gambar 4 . Diagram kontrol menjelaskan kerja sistem secara berurutan. Pergerakan aktuator secara spesifik dijelaskan dalam diagram ini. Sistem dimulai dengan membaca data potensiometer. Namun dalam realisasi untuk pembacaan jarak potensiometer dan kecepatan putar tetap ditampilkan secara real time dalam antarmuka (LabView). Pada sistem ini dimulai dengan pembacaan apakah silinder berada dalam posisi maksimal. Dalam sistem ini pergerakan dibatasi karena kesalahan dalam pembuatan sistem mekanik yaitu maksimal sepanjang $8 \mathrm{~mm}$. Sehingga posisi tersebut merupakan posisi maksimal dari sistem. Namun pada sebenarnya silinder dapat mencapai posisi $60 \mathrm{~mm}$.

Diawali dengan membaca data potensiometer sistem kemudian akan mendeteksi apakah silinder berada dalam posisi maksimal atau tidak. Apabila silinder tidak dalam posisi maksimal namun tetap berputar maka eksekusi program akan menunggu hingga kecepatan putar turbin melebihi $40 \mathrm{rpm}$. Sedangkan apabila kondisi rpm sama dengan 0 maka silinder akan mundur kembali untuk 
melakukan penangkapan angin. pada sistem ini silinder akan mundur pada posisi potensio $3 \mathrm{~mm}$. Posisi ini dipilih agar pembacaan mikrokontroler untuk memerintahkan relay dapat dilaksanakan tanpa adanya konflik karena pembacaan yang terlalu dekat.

Sedangkan untuk pembacaan kecepatan putar turbin angin apabila telah melebihi $40 \mathrm{rpm}$ maka sistem akan memerintahkan silinder untuk melakukan pitching. Pitching pada sistem ini hanya dapat dilakukan sepanjang $8 \mathrm{~mm}$. Hal ini dikarenakan keterbatasan dalam pembangungan sistem mekanik. Jika potensiometer sudah membaca lebih dari $7.5 \mathrm{~mm}$ maka silinder akan bertahan dalam posisi tersebut. Hal ini merupakan penerapan dari sistem servo pneumatik yang membuat silinder dapat berhenti dalam posisi manapun.

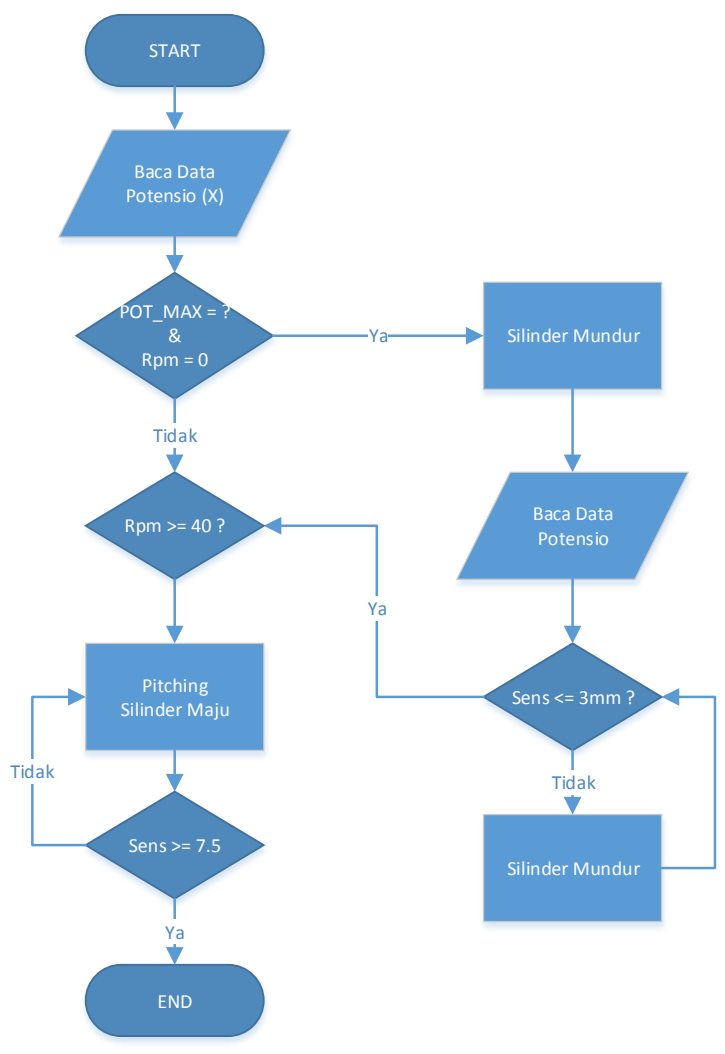

Gambar 4. Diagram alir kontrol utama

\section{HASIL PENGUJIAN}

\subsection{Hasil Pengujian Servo Pneumatik}

Aplikasi smart blade pada turbin angin seperti yang ditunjukkan pada gambar 5 dimana (1) adalah bagian transfer mekanik dari pergerakan maju mundur silinder menjadi pergeseran sudut pitch, (2) menunjukkan sensor encoder, bagian (3) menunjukkan silinder, bagian (4) menunjukkan sensor posisi potensiometer dan bagian (5) adalah blade foil atau lembar bilah.

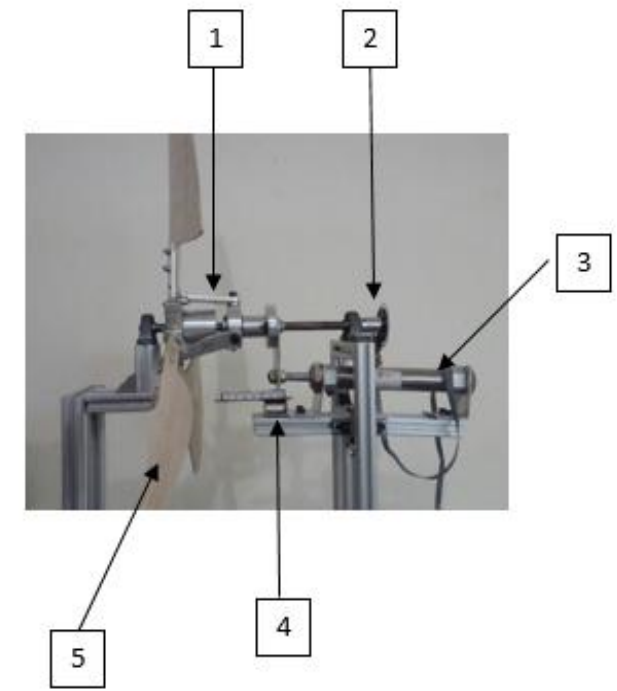

Gambar 5. Aplikasi smart blade pada prototype turbin angin

Pengujian pergerakan silinder ini bertujuan untuk mengetahui respon silinder saat diminta untuk mencapai jarak tertentu secara acak. Selain itu tujuan dilakukannya pengujian ini adalah untuk mengetahui apakah servo pneumatik dapat diaplikasikan pada sistem mekanik atau tidak. Pengujian dilakukan secara manual melalui perangkat lunak Arduino IDE.

Pengujian ini memiliki hasil rata-rata error $7,13 \%$. Pengujian dilakukan dengan tiga langkah. Langkah pertama yaitu pengujian dengan jarak bertambah $10 \mathrm{~mm}$. Pengujian kedua dilakukan dengan mengurangi jarak sebesar $10 \mathrm{~mm}$. Sedangkan pengujian terakhir dilakukan dengan mengambil jarak yang acak. Dari percobaan ini dapat disimpulkan bahwa error memiliki batas atas dan bawah masing-masing sebesar $3 \mathrm{~mm}$. Apabila batas error dibuat menjadi kurang dari $3 \mathrm{~mm}$ maka respon silinder tidak akan berhenti dan berusaha untuk berhenti pada nilai yang pas (maju-mundur). Hal ini terjadi karena kemampuan maju silinder, katup, dan flow control yang membutuhkan tekanan minimum untuk beroperasi secara lebih teliti. Sehingga setelah melakukan berbagai percobaan didapatkan batas error atas dan bawah masing-masing sebesar $3 \mathrm{~mm}$. Tabel berikut menunjukkan hasil percobaan pergerakan silinder pneumatik.

Tabel 1 Data pengujian silinder tanpa pembebanan 


\begin{tabular}{|r|r|r|r|}
\hline $\begin{array}{c}\text { Jarak } \\
\text { pembacaan } \\
(\mathrm{mm})\end{array}$ & $\begin{array}{c}\text { Jarak } \\
\text { diminta } \\
(\mathrm{mm})\end{array}$ & $\begin{array}{c}\text { Error } \\
(\mathrm{mm})\end{array}$ & Error (\%) \\
\hline 12,24 & 10 & 2,24 & 22,4 \\
\hline 22,59 & 20 & 2,59 & 12,95 \\
\hline 32,23 & 30 & 2,23 & 7,43 \\
\hline 40,64 & 40 & 0,64 & 1,6 \\
\hline & & & \\
\hline 31,01 & 30 & 1,01 & 3,37 \\
\hline 20,89 & 20 & 0,89 & 4,45 \\
\hline 11,04 & 10 & 1,04 & 10,4 \\
\hline & & & \\
\hline 35,2 & 35 & 0,2 & 0,57 \\
\hline 20,56 & 20 & 0,56 & 2,8 \\
\hline 41,09 & 45 & 3,91 & 8,69 \\
\hline 3 & 3,12 & 0,12 & 3,85 \\
\hline & & & \\
\hline
\end{tabular}

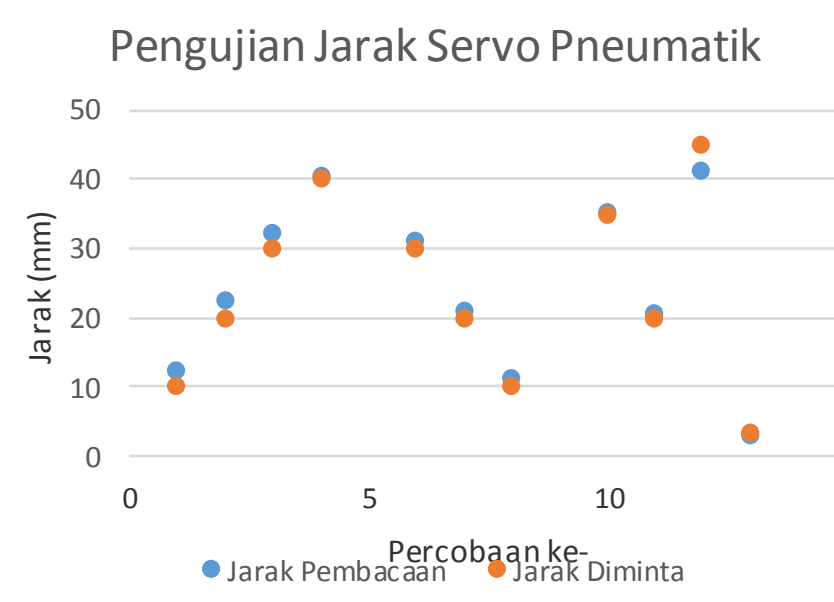

blade mengalami penurunan dalam menangkap angin.

Dalam aplikasi yang lebih akurat maka dapat menggunakan sistem actuator hybrid pneumatik dan piezoelektrik seperti yang dilakukan oleh Chiang [7] dimana menggunakan silinder pneumatik yang memiliki langkah besar, kecepatan tinggi dan actuator piezoelektrik yang dapat bekerja dengan halus pada setiap perpindahan posisi di setiap sumbu.

\subsection{Hasil Pengujian Keseluruhan Sistem}

\section{- Pengujian tanpa Pitching}

Pada pengujian ini baling-baling berputar dengan menggunakan angin yang bersumber dari kipas angin. Pengujian dilakukan dengan memakai sumber angin dari fan yang memiliki rentang kecepatan angin yang tidak terlampau besar yaitu hanya dari $2.6 \mathrm{~m} / \mathrm{s}-4 \mathrm{~m} / \mathrm{s}$

Tabel 2 Pengukuran umum kecepatan sumber angin

\begin{tabular}{|c|r|r|r|}
\hline Klasifikasi & Tingkat & \multicolumn{1}{|c|}{$\begin{array}{c}\text { Kecepatan } \\
(\mathrm{rpm})\end{array}$} & $\begin{array}{c}\text { Kecepatan } \\
\text { rata-rata } \\
(\mathrm{m} / \mathrm{s})\end{array}$ \\
\hline \multirow{3}{*}{ UMUM } & 1 & 722 & 2,648 \\
\cline { 2 - 4 } & 2 & 846 & 2,924 \\
\cline { 2 - 4 } & 3 & 981 & 3,904 \\
\hline
\end{tabular}

Setelah didapatkan kecepatan rata-rata pada sumber angin maka dilakukan pengujian perputaran baling-baling. Pengujian dilakukan dengan angin bebas dari sumber angin tanpa 15menggunakan lorong angin. pengujian perputaran baling-baling tanpa pitching dilakukan dengan cara memberikan sumber angin pada turbin tanpa melakukan pitching. Pengujian kecepatan turbin angin tersaji pada tabel berikut.

\section{Tabel 3 Pengukuran kecepatan turbin angin tanpa} pitching

Dapat dilihat dari table 1 pada uji jarak yang pendek akan mendapatkan nilai eror yang lebih besar dibandingkan dengan pembacaan jarak yang lebih panjang. Hal ini seperti yang sudah diperkirakan oleh Saravanakumar [6] dimana sistem kontrol dengan menggunakan pneumatik akan menghadapi hal-hal ketidakakurasian dikarenakan karakteristik non linier dari sistem penumatik akibat pengaruh dari gaya gesekan udara, sifat termodinamika dari udara yang bertekanan dan ketidaklinieran dari katup. Namun untuk aplikasi smart blade dimana tidak memerlukan perpindahan posisi yang sangat akurat, maka nilai eror seperti yang ditunjukkan masih memadai. Karena yang diperlukan pada smart blade adalah perpindahan posisi sehingga

\begin{tabular}{|c|r|r|}
\hline Klasifikasi & Tingkat & $\begin{array}{c}\text { Kecepatan } \\
\text { (rpm) }\end{array}$ \\
\hline $\begin{array}{c}\text { Pengukuran } \\
\text { tachomode } \\
\text { contact }\end{array}$ & 1 & 0 \\
\cline { 2 - 3 } & 2 & 19 \\
\hline
\end{tabular}

Hasil dari pengujian didapatkan bahwa pada kecepatan 1 turbin angin tidak berputar sama sekali meskipun posisi sumber angin berada pada posisi yang berbeda. Sedangkan untuk kecepatan 2 dan 3 turbin mulai berputar meskipun kecepatan putar turbin sangat jauh berbeda dengan 
kecepatan putarsumber angin. hal ini dapat terjadi karena beberapa faktor yaitu;

- Baling-baling turbin angin yang terbuat dari kayu balsa sehingga daya angkat tidak cukup kuat untuk memutarkan turbin angin,

- Konstruksi mekanik tidak terlalu ringan untuk berputar sehingga menyebabkan turbin angin sulit melakukan putaran.

\section{- Pengujian dengan Pitching}

Karena turbin berputar dalam keadaan maksimal dapat mencapai kecepatan putar $40 \mathrm{rpm}$. Sehingga nilai $40 \mathrm{rpm}$ pada program digunakan sebagai nilai cut out turbin angin untuk melakukan pitching. Sedangkan setelah melakukan pitching atau pengereman maka kecepatan putar turbin angin dapat mencapai $0 \mathrm{rpm}$. Hal ini karena saat pengereman kecepatan angin yang diterima oleh baling-baling tidak dirubah menjadi gerak angkat (lift).

Tabel 4 Pengujian Keseluruhan Sistem

\begin{tabular}{|c|c|c|c|}
\hline $\begin{array}{c}\text { Kecepatan } \\
\text { Setelah } \\
\text { Pitching }\end{array}$ & $\begin{array}{c}\text { Kecepatan } \\
\text { Sebelum } \\
\text { Pitching }\end{array}$ & $\begin{array}{c}\text { Posisi } \\
\text { Silinder } \\
\text { Sebelum } \\
\text { Pitching }\end{array}$ & $\begin{array}{c}\text { Posisi } \\
\text { Silinder } \\
\text { Setelah } \\
\text { Pitching }\end{array}$ \\
\hline 0 rpm & $40 \mathrm{rpm}$ & $3.12 \mathrm{~mm}$ & $8 \mathrm{~mm}$ \\
\hline
\end{tabular}

Pada sistem ini hanya dapat dilakukan pengujian sistem kes,eluruhan saat posisi no pitching dan posisi full pitching. Hal ini dikarenakan keterbatasan sistem mekanik yang hanya mampu memberikan pannjang gerakan silinder sebesar $8 \mathrm{~mm}$.

\section{KESIMPULAN}

Berdasarkan hasil penelitian ini, dapat disimpulkan beberapa hal mengenai rancang bangun pitch kontrol pada prototipe turbin angin berbasis servo pneumatik, seperti :

1. Kendali pitch pada turbin angin dengan menggunakan servopneumatik dapat membatasi kecepatan putar turbin angin

2. Servo pneumatik meski terkendala karakteristik nonlinier dari angin sehingga akurasinya dan presisinya yang rendah, namun masih memadai pada aplikasi kontrol pitch pada turbin angin

3. Servo pneumatik yang diterapkan pada sistem hanya mampu bergerak sepanjang $8 \mathrm{~mm}$
4. Kecepatan putar turbin angin tanpa melakukan pitching (kecepatan angina di bawah set point) dapat mencapai $40 \mathrm{rpm}$. Sedangkan kecepatan putar turbin angin setelah pitching (kecepatan angina di atas set point) dapat mencapai $0 \mathrm{rpm}$.

\section{SARAN}

Dalam pengembangan penelitian pitch kontrol prototipe turbin angin berbasis servo pneumatik masih kurang pada sistem kontrol aliran udara pneumatik. Kontrol aliran udara adalah salah satu komponen utama servo pneumatik sehingga jika belum ada sistem kontrol aliran udara maka rotor akan mengalami kesulitan untuk kembali berputar setelah proses pitching. Rotor dapat kembali berputar dengan pengaturan secara manual yaitu kontrol aliran udara diputar dengan tangan agar aliran udara cukup untuk mendorong silinder mundur agar rotor kembali berputar

\section{Daftar Pustaka}

Pada teks, dafar pustaka harus disitasi dengan menuliskan no urut daftar pustaka

[1] Bryce B.Aquino,"New Generator Control Algorithms for Smart Bladed Wind Turbines to Improve Power Capture in Below Rated Conditions," Master Theses, University of Massachusetts Amherst, pp 6, September 2014

[2] Bossanyi, E, "Individual blade pitch control for load reduction" Wind energy, 6(2), pp.119128, 2003

[3] Andersen, P.B.,"Load alleviation on wind turbine blades using variable airfoil geometry (2D and 3D study)", Technical University of Denmark, 2005

[4] AR.Jhe.PhD,"Wind Turbine Technology", pp 96, 2011

[5] Sandra Eriksson, Hans Bernhoff, Mats Leijon," Evaluation of different turbine concepts for wind power, Renewable and Sustainable Energy Reviews, Vol.12 1419-1434, 2008

[6] D.Saravanakumar ,B.Mohan, T. Muthuramalingam, A review on recent research trends in servo, pneumatic positioning systems, Precision Enginering (49) pp 481-492, 2017

[7] Chiang MH.,"Development of X-Y servopneumatic-piezoelectric hybrid actuator for position control with high response,large stroke and nanometer accuracy,"Sensors Vol.10(4) pp 2675-93, 2010 